\title{
PROXIMACIÓN AL HIGIENISMO EN LA
ARQUITECTURA DE RAFAEL GUASTAVINO
}

\author{
FERNANDO VEGAS LÓPEZ-MANZANARES \\ Universitat Politècnica de València \\ fvegas@cpa.upv.es \\ CAMILLA MILETO \\ Universitat Politècnica de València \\ cami2@cpa.upv.es \\ VÍCTOR M. CANTERO SOLÍS \\ Universitat Politècnica de València \\ victorcanterosolis@gmail.com
}

Resumen: La obra de Rafael Guastavino Moreno (1842-1908) está vinculada habitualmente a la construcción con bóveda tabicada, un sistema constructivo tradicional originario del Levante peninsular que este maestro de obras combinó con el mortero de cemento para erigir un gran número de edificios de muy diverso tipo tanto en Barcelona como posteriormente, casi siempre en calidad de constructor, en Estados Unidos. Sin embargo, estos autores han defendido en otras ocasiones la versatilidad de Guastavino como maestro de obras y hasta qué punto la bóveda tabicada no supuso en un principio el mérito único ni principal de su trayectoria profesional. La bóveda tabicada representó una herramienta más en el conjunto de sus habilidades, entre las cuales cabría destacar su talento para proyectar edificios de viviendas en el nuevo ensanche barcelonés, su destreza en el empleo de estructuras metálicas, su habilidad como constructor, y su pericia en el diseño de la carpintería. Este artículo viene a mostrar una vertiente en gran parte inédita de este polifacético maestro de obras en torno a las corrientes del higienismo que caracterizaron la segunda mitad del siglo XIX.

Palabras clave: Arquitectura / Guastavino / higienismo / ventilación / aislamiento / saneamiento / reforma interior.

\section{ON HYGIENISM IN THE ARCHITECTURE OF RAFAEL GUASTAVINO}

Abstract: The work of Rafael Guastavino Moreno (1842-1908) is usually linked to construction with tile vaults, a traditional constructive system originally from eastern Spain. Guastavino combined these with cement mortar to build many constructions of different types, both in Barcelona and later as a developer in the United States. While the authors have previously defended Guastavino's versatility as a master builder, tile vaults were by no means the first or most important achievement of his career. Construction with tile vaults was just one of many skills. Among these it is worth highlighting his talent for designing residential buildings in the newly built Eixample district in Barcelona, his skilled work with metal structures, and as a master builder the study examines its relation to the currents of the social hygiene movement characteristic of the second half of the 19th century.

Key words: Architecture / Guastavino / social hygiene movement / air circulation / isolation / sanitation / interior design.

* Fecha de recepción: 15 de octubre de 2019 / Fecha de aceptación: 23 de marzo de 2020. 
El higienismo es un movimiento nacido en el siglo XIX en paralelo con la aglomeración progresiva de la población en las ciudades industriales, que vino a acentuar la pobreza y el hacinamiento que ya venía sufriendo una buena parte de la población. Benefactores, médicos, pensadores, gobernantes, pero también arquitectos y urbanistas brindaron propuestas diversas para mejorar sus condiciones de vida y, en consecuencia, evitar enfermedades como el cólera que, de manera reiterada, seguían abatiendo sobre todo a los más desfavorecidos. El interés no era únicamente altruista. Las epidemias de viruela en el siglo XVIII y las pandemias del cólera del siglo XIX no solo diezmaban la población, sino que también provocaban importantes recesiones económicas en los países afectados.

Los esfuerzos de la corriente higienista se concentraron sobre todo en mejorar las condiciones ambientales, esto es, el agua, el aire y el sol. El agua, cuya contaminación era la principal responsable de los brotes del cólera, comenzó a canalizarse mediante la entubación de acequias y cloacas y el progresivo suministro de agua potable de manera independiente de los tradicionales pozos, que a menudo se contaminaban con las aguas fecales. El aire húmedo, enrarecido o viciado, derivado de la falta de ventilación de los espacios internos, de la contaminación por parte de las industrias y la calefacción por carbón y de las sustancias orgánicas en descomposición, fue igualmente objeto de preocupación. Por último, el estudio del soleamiento necesario en las viviendas acompañó las propuestas urbanísticas de finales de siglo y este prurito se prolongó al menos hasta el diseño de las urbanizaciones de los años heroicos del Movimiento Moderno.

El valenciano Rafael Guastavino Moreno (18421908), en sintonía con el espíritu de los tiempos que le tocó vivir y de manera coherente con el carácter poliédrico de su perfil profesional derivado de su formación como maestro de obras en la Escuela de la Lonja de Barcelona, también se ocupó activamente de esta cuestión en sus obras y escritos, tanto a nivel arquitectónico como urbanístico, tanto en su etapa española como en la estadounidense. Sin embargo, curiosamente, esta vertiente de la obra de Rafael Guastavino no ha sido apenas tratada hasta la fecha de manera específica por sus estudiosos, que se han centrado principalmente en sus construcciones de bóveda tabicada. ${ }^{1}$ El acento puesto por él mismo en las bondades de su construcción cohesiva, basada en la asimilación y conglomeración de los materiales aparejados en una fábrica -especialmente en una bóveda tabicada recibida con el novedoso mortero de cemento eventualmente atirantada-, frente a la construcción mecánica o por gravedad, basada en el equilibrio y contraposición de las masas, ${ }^{2}$ ha relegado a un segundo plano esta vertiente de su pensamiento y obra.

Entre otros casos nacionales e internacionales, las ciudades de Valencia y Barcelona promovieron sendos ensanches como solución a la escasez de solares edificables para una población en crecimiento, a las deficiencias higiénicas del trazado urbano y las viviendas y al alto precio de los alquileres para los alojamientos. $^{3}$ El ensanche de Barcelona fue proyectado en tres fases por el ingeniero catalán Ildefonso Cerdá Suñer (1815-1876), a saber, un anteproyecto (1855), una primera propuesta (1859) y el proyecto definitivo (1863), que serviría de base a la ampliación de la ciudad. Por otra parte, tras una propuesta pionera de 1777, el proyecto del ensanche de Valencia fue iniciado en 1857, terminado en 1858 y aprobado por el Gobernador de la Provincia el 13 de julio de $1859^{4}$ aunque se quedó en agua de borrajas hasta 1884, cuando se diseñó el ensanche definitivo de la ciudad. ${ }^{5}$ Rafael Guastavino vivió a caballo de Valencia y Barcelona, en el momento en que se alumbraron ambos ensanches y destacó entre sus compañeros de generación, precisamente, por el número y la calidad de sus edificios proyectados en el ensanche de la segunda ciudad.

\section{El Ensanche de Valencia}

Rafael Guastavino trabajó como delineante en un estudio de arquitectura de Valencia desde 1857 hasta 1859. El número de arquitectos y maestros de obra activos antaño en esta ciudad apenas llegaba a la veintena. Estos autores han especulado con la posibilidad de que trabajara con Antonino Sancho Arango (1805-1876), Timoteo Calvo Ibarra (1799-1879) o Sebastián Monleón Estellés (18151878) en virtud de las relaciones profesionales de su padre, ebanista de profesión, ${ }^{6}$ especialmente con

\footnotetext{
1 Entre los estudios más significativos, destaca por ejemplo OCHSENDORF, John, 2014.

2 GUASTAVINO, Rafael, 1893b, p. 2.

3 TABERNER, Francisco, 1987, p. 41.

4 TABERNER, Francisco, 1987, p. 52.

${ }^{5}$ BENITO, Daniel, 1983, p. 3.

${ }^{6}$ VEGAS, Fernando; MILETO, Camilla, 2012, p. 134
} 
Sebastián Monleón Estellés, por su dominio de técnicas muy diversas (ladrillo, madera, metal, vidrio) aplicadas en edificios de la ciudad y su condición de fabricante de azulejos en aquellos mismos años. Existe también otra hipótesis no considerada hasta el momento que es su posible colaboración con el arquitecto Ramón María Ximénez Cross (18291865), que en 1858 realizó un detallado levantamiento de la Lonja de Valencia, publicado años más tarde en 1876 en el cuaderno $n^{\circ} 86$ de la gran monografía Monumentos Arquitectónicos de España coordinada por Amador de los Ríos. La minuciosa reproducción a escala de este edificio valenciano por parte de Rafael Guastavino, como pabellón español para la Exposición de Chicago de 1893, no solo remite con certeza a este levantamiento como referencia principal ineludible, dada la premura con la que se concurrió al certamen, ${ }^{7}$ sino que también podría indicar un conocimiento detallado del monumento derivado de una eventual participación como delineante en estos dibujos. Además, Ximénez fue el arquitecto más viajero y versado en mundología de su generación, un posible ejemplo para el inquieto Guastavino, si se confirmara esta colaboración: fue pensionado en Roma, visitó Grecia y estaba al día de las publicaciones y novedades arquitectónicas de Alemania, Francia e Inglaterra. ${ }^{8}$

El Plan General de Ensanche de Valencia de 1858 estuvo precisamente a cargo de los arquitectos Sebastián Monleón, a la sazón, concejal de Valencia, Antonino Sancho y Timoteo Calvo, del cronista de la ciudad Vicente Boix Ricarte (1813-1880) y del doctor Manuel Encinas (1799-1868), también concejal y presidente del Instituto Médico Valenciano, como asesor en materia higienista. La presencia de estos arquitectos responde a su condición de arquitectos mayores del Ayuntamiento de Valencia, pero Antonino Sancho también había destacado por una colección de veinte artículos escritos entre 1848 y 1854 publicados conjuntamente en 1855 bajo el título "Mejoras materiales de Valencia". De hecho, la parte de la memoria relativa a las condiciones sociales de la ciudad proviene directamente de la pluma de Antonino Sancho. ${ }^{9} \mathrm{La}$ presencia de un médico entre los firmantes de un proyecto de ensanche es un hecho completamente inusual que brinda la medida de la sensibilidad por el higienismo que imperaba antaño en el consistorio valenciano.

Manuel Encinas y Navarro (1799-1868) nació en Valencia en el seno de una familia de labradores oriundos de Granada, y estudió medicina en la Universidad Literaria de la ciudad. ${ }^{10}$ Desde su plaza de profesor en la facultad de medicina, poco a poco fue incorporándose a la vida pública animado por su conocimiento de los problemas urbanos en materia de salubridad y su interés por contribuir activamente en sus mejoras. En 1849 Manuel Encinas era académico de la Academia de Medicina y Cirugía y además Depositario de la Universidad Literaria. ${ }^{11}$ Ocupó la presidencia del Instituto Médico Valenciano durante dos años hasta que cesó como tal con su nombramiento como Regidor del Ayuntamiento Constitucional de la Ciudad en la Sesión Ordinaria del 4 de enero de 1859. ${ }^{12}$

La memoria del Ensanche de 1858 denunciaba la falta de ventilación de los dos tercios más humildes de las viviendas de la ciudad, la escasez de iluminación de los interiores y el carácter desaseado y sombrío de algunas de sus calles, condiciones que enarbolaba para reclamar perentoriamente la implantación del plan del ensanche. ${ }^{13}$

Este plano de ensanche quedaría como referencia en la cartografía local durante los años sucesivos, como se demuestra en el plano topográfico de la ciudad que publicó el arquitecto Ramón $\mathrm{M}^{\mathrm{a}}$ Ximénez en 1860, que asumió el Plan del Ensanche de 1858 partiendo de la verificación, corrección y ampliación de las construcciones y alineaciones del plano de Vicente Montero de Espinosa de 1852. ${ }^{14}$ Este plano se comenzó a preparar en 1857, en paralelo con el desarrollo del proyecto de ensanche, cuando el litógrafo Antonio Pascual y Abad elevó la solicitud al Ayuntamiento de Valencia. ${ }^{15}$

Se debe recordar que Valencia había sufrido pocos años antes, en 1854, una de sus peores epidemias de cólera donde, por cierto, había fallecido Josefa

\footnotetext{
7 VEGAS, Fernando, 1999, p. 257.

8 CABRERA, Inés, 2017, p. 252-292.

9 TABERNER, Francisco, 2014, p. 289.

${ }^{10}$ AU. Ex. 129/7. Obtuvo finalmente el grado de Doctor en Medicina con calificación de sobresaliente el 13 de julio de 1840.

11 Poseía su residencia habitual en la calle Linterna número 3.

12 Manuel Encinas Navarro expiró el 18 de diciembre de 1868 en su domicilio de la calle Linterna.

13 SANCHO, Antonino et. al., 1859.

14 LLOPIS, Amando; PERDIGÓN, Luis; TABERNER, Francisco, 2004, p. 78-79.

15 TABERNER, Francisco, 2014, p. 292.
} 
Ebrí Nadal (1786-1854) (Registro Civil 1854), abuela del maestro de obras Rafael Guastavino y principal nexo de unión de este con su tatarabuelo también maestro alarife Juan José Nadal (16901762). En los últimos años de su vida Josefa Ebrí Nadal, ya viuda y con escasos medios, había sido carbonera y, debido a su magra economía tuvo su domicilio en bajos de edificios, probablemente asociados a sus depósitos de carbón, en ambientes húmedos no demasiado soleados ni ventilados: en un primer momento, junto con su hija y madre del maestro de obras Pascuala Moreno y su familia respectiva unos años hasta que nació Rafael Guastavino (1842) en la calle Puñalería 14; y posteriormente junto a su hija soltera Esperanza Moreno, costurera, en la calle Horno de los Apóstoles 7 (1843), la Travesía del Miguelete 5 (1845) y en la calle Mañam 15 (1854). Falleció en su vivienda de la estrecha calle Mañam, en el barrio del Mercado, uno de los más afectados por las epidemias de cólera del siglo XIX, a juzgar por el plano de mortalidad de la epidemia de cólera de 1884-85 que, como el plano de Ramón María Ximénez, también asumió el proyecto del Ensanche de $1858 .{ }^{16}$ Curiosamente, el arquitecto Ramón María Ximénez también moriría de cólera en Valencia en la epidemia de 1865.

\section{El Ensanche de Barcelona}

En Barcelona, tras el anteproyecto inicial de Ildefonso Cerdá de 1855 igualmente espoleado por la epidemia de cólera en la ciudad de 1854, las propuestas sucesivas para el ensanche de Barcelona no estuvieron exentas de polémica. Ildefonso Cerdá, ingeniero de obras públicas en contacto con las ideas higienistas e influido por el socialismo utópico de Étienne Cabet (1788-1856), trabajó en diversos proyectos antes de afincarse en Barcelona. Entre otros, dirigió las obras de abastecimiento de agua potable de Valencia en la década de 1840 que revertirían en una mejora de su salubridad. ${ }^{17}$

En el ensanche de Barcelona puso en práctica sus ideas urbanizadoras basadas en los requisitos de la circulación, con amplias avenidas y chaflanes, y del higienismo, introduciendo factores como el asolea- miento, la ventilación, la oxigenación o el arbolado. Cerdá dividió su ensanche entre vías, espacio público de encuentro, circulación y servicios, y manzanas, espacio para la vida privada. ${ }^{18}$ Su proyecto se ilustró también con secciones urbanas, instalaciones y alcantarillado soterrado bajo la vía pública. Aunque sus ideas iniciales fueron en parte pervertidas posteriormente por la especulación urbanística, el legado de sus teorías, ${ }^{19}$ es incontestable. Concibió el diseño igualitario de su trama urbana para mejorar las condiciones higiénicas y la fluidez del tráfico y la ventilación. Su objetivo era la calidad de vida, con cuestiones que iban desde el estudio del entorno físico, la propiedad del suelo, altura de cornisas, redes de alcantarillado, equipamientos, densidad de población y la distancia máxima que debía existir entre cualquier vivienda y una zona ajardinada.

Pero ¿quién pudo influir verdaderamente en Cerdá para centrar su interés en el higienismo urbano? El libro Elementos de higiene pública, o el arte de conservar la salud de los pueblos (1862) de Pedro Felipe Monlau brinda una posible pista. ${ }^{20}$ Pedro Felipe Monlau y Roca (1808-1871) fue un médico barcelonés con amplia formación humanística, subdelegado de Medicina y Cirugía y miembro de la Junta de Salubridad en un distrito barcelonés. ${ }^{21} \mathrm{Su}$ trayectoria en materia de higiene urbana fue imparable. Recaló en Madrid formando parte de numerosas comisiones y juntas municipales encargadas de asuntos de salubridad pública estatal. Fue co-redactor con los médicos Mateo Seoane Sobral (1791-1870) y Francisco Méndez Álvaro (1803-1883) de la Ley Orgánica de Sanidad del 28 de noviembre de 1855. Monlau y Cerdá coincidieron residiendo en Madrid y quizá también en Barcelona. El primero pudo haber influido en el segundo, o haber compartido ambos la misma inquietud por la higiene urbana de los ambientes más progresistas de aquellos tiempos.

Pedro Felipe Monlau fue víctima de una represalia política, y residió dos años en Valencia, ${ }^{22}$ de 1844 a 1846, periodo en el que trabajó en el Hospital Militar. ¿Tendría eventual contacto y relación per-

${ }^{16}$ LLOPIS, Amando; PERDIGÓN, Luis; TABERNER, Francisco, 2004, p. 78-79; TABERNER, Francisco, 2014, p. $293-294$.

17 PALOMERO, José Antonio; ALVARIÑO, Patricia, 2016, p. 47.

18 Grupo 2C (TARRAGÓ et al.), 2009, p. 104-117.

19 CERDÁ, Ildefonso, 1867.

20 TABERNER, Francisco, 1987, p. 45.

${ }^{21}$ CAMPOS MARTín, Ricardo. "Pedro Felipe Monlau y Roca" (en línea). En http://dbe.rah.es/biografias/13044/pedro-felipemonlau-y-roca (Fecha de consulta: 14-04-2019).

22 En este año se publicó el Reglamento de Policía Urbana y Rural de Valencia cuyo Capítulo IV (Arts. 32 a 48) se titula Higiene de las viviendas. 
sonal en estos dos años con el entonces médico valenciano Manuel Encinas y Navarro, responsable principal en materia de higienismo en el proyecto de Ensanche valenciano de 1858? Es fácil que así fuera $y$, de tal forma, sería posible establecer un triángulo formado por Cerdá, Monlau y Encinas del que pudieron nutrirse todos los representantes en materia de reformismo urbano en la ciudad de Valencia, entre ellos Rafael Guastavino y como se verá, de manera subsidiaria su hermano Carlos.

\section{Las viviendas diseñadas por Rafael Guastavino Moreno en el Ensanche de Barcelona}

Rafael Guastavino asume de manera inmediata el Ensanche de Cerdá hasta el punto de que se convierte en el maestro de obras que más edificios erige en el nuevo trazado del mismo durante sus primeros diez años de existencia, solo después de Josep Oriol Mestres i Esplugas (1815-1895), arquitecto favorito de la alta burguesía de antaño. Estos primeros edificios del ensanche, que combinaba viviendas unifamiliares con edificios plurifamiliares de discretas dimensiones, sufrió muy pronto la presión de la especulación, al punto que no se conservan demasiados edificios de aquella época. En sus viviendas para el Ensanche, Guastavino realizó interesantes aportaciones que las convirtieron en referencia para los arquitectos de la generación posterior del Modernismo. ${ }^{23}$ Entre ellas, cabe destacar por su pertinencia en este artículo: ${ }^{24}$

-La creación de generosos patios nucleares de ventilación e iluminación integrados, por ejemplo las casas diseñadas por Guastavino para Miguel Buxeda (1863), Víctor Blajot (1871) (Fig. 1), Camilo Juliá (1871), Andreu Anglada (1873), en detrimento de la multiplicación y dispersión de patinillos menores en otros edificios iniciales del ensanche diseñados por otros profesionales, como la Casa para los solares nº 6 y 15 (1864) de Jeroni Granell Barrera, la Casa Santiago García Pinillos (1870) de Josep Oriol Mestres, la Casa Lorenzo Fradera (1872) de Josep Domínguez Valls, etc.

-La introducción de entresuelos frente a los tradicionales semisótanos, sin duda para aumentar la superficie edificable, pero también como método de evitar la humedad en la planta baja e iluminar y ventilar los espacios parcialmente soterrados, como el caso de la pionera Casa Buxeda (1863).

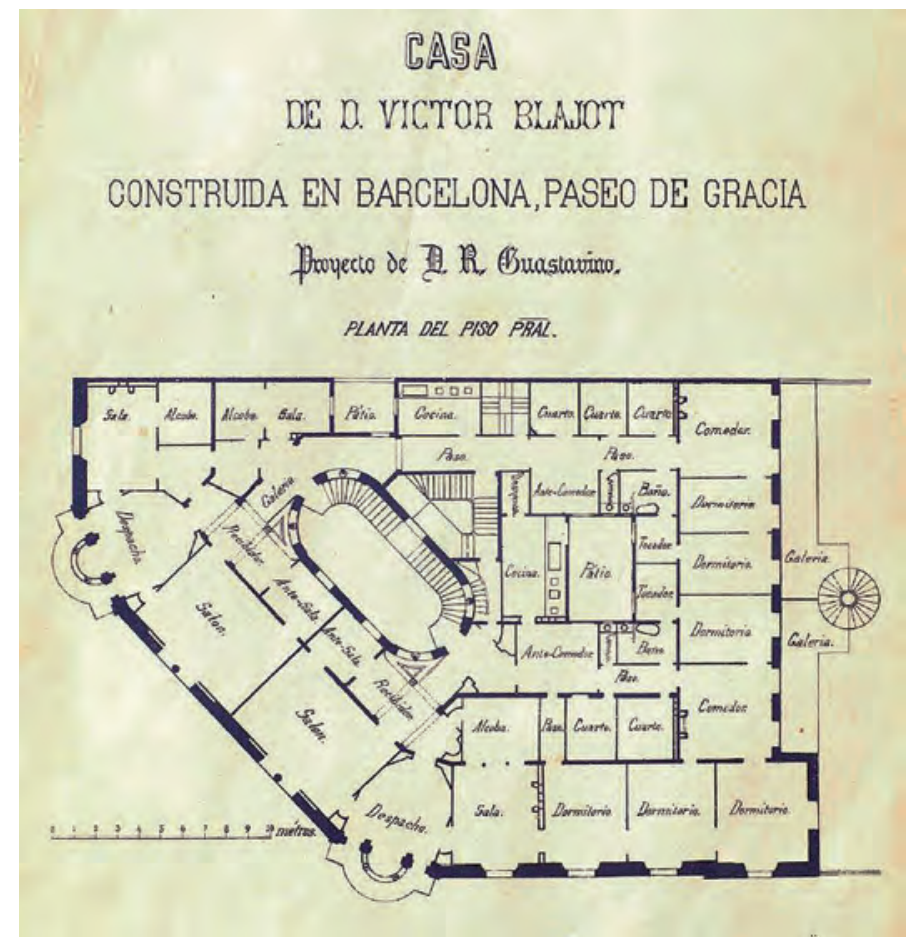

Fig. 1. Planta del piso principal de la Casa Blajot (1871) de Rafael Guastavino, con rótulos indicativos del uso de cada espacio, donde se observa la presencia de su gran patio de manzana con la escalera, los miradores en las esquinas, la galería posterior y escalera de caracol de acceso al jardín. Autor y fecha desconocidos (AHCB, registro no 3736, CO2.01 Subcolección de planos de edificios).

-La profusión de miradores acristalados en sus fachadas en chaflán, en especial en las esquinas, y de tragaluces, como los lucernarios de las cajas de escalera o el fuste de la escalera de caracol de acceso al jardín de la Casa Blajot (Fig. 1), coronado con una claraboya que ilumina el sótano.

-La creación de generosas galerías porticadas con columnas de fundición frente a los jardines posteriores como en el Palacete Oliver (1869) y en la Casa Blajot (1871), o balconadas como en la Casa Montalt (1871), con la incorporación de ingeniosos accesos independientes al jardín para los vecinos de diversas plantas, como la Casa Blajot (1871) (Fig. 1).

-La separación entre las cocinas y los excusados con un espacio intermedio para mejorar la salubridad de las primeras, además de la ventilación directa de los mismos, como se puede deducir de una ob-

23 ROGENT, Elías; DOMÉNECH, Lluís, 1897, Láminas LXV y XCIII y texto que les acompaña.

24 Un listado bastante completo de sus obras en Barcelona se puede encontrar en LUENGO PÉREZ, Noelia, 2016. 


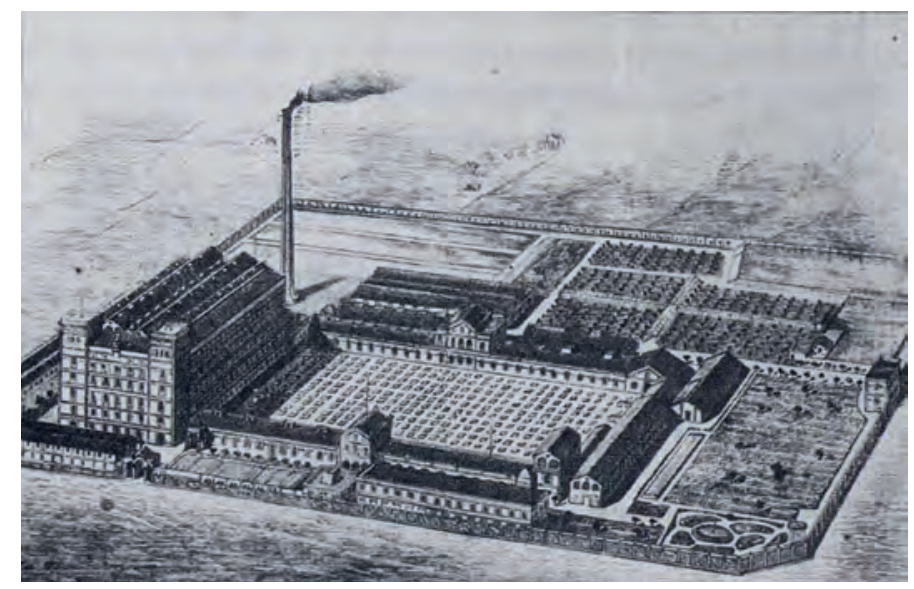

Fig. 2. Perspectiva de la fábrica Batlló (1868-1870), que marcó un antes y un después en la arquitectura industrial de Barcelona, también en cuestiones de higienismo (A. Rigalt, AHCB, registro 12385 ).

servación atenta de las plantas de distribución de todos sus edificios.

-La promoción de forjados de bóveda con cámara intermedia y tabiquillos para sostener el tablero superior y de los muros dobles con cámara intermedia para evitar la humedad y la condensación, además de mejorar las condiciones térmicas.

Trazas de estas ideas higienistas aplicadas en sus edificios se pueden encontrar igualmente en sus escritos, desde la bondad de la interposición de cámaras en los muros de cerramiento y en las bóvedas de forjados y cubiertas, ${ }^{25}$ la necesidad de erradicar el contacto directo de los vapores de las letrinas con la cocina de la casa ${ }^{26}$ y la ventilación directa de todas las estancias de la casa, incluidos retretes y cuartos de baño, la evitación de la humedad de las casas y de las fugas de gases y emanaciones nocivas entre viviendas y el empleo de tubos no absorbentes para los desagües, ${ }^{27}$ hasta el fomento de las particiones sólidas de panderete de ladrillo recibido con yeso en el interior de las viviendas frente a otras opciones de tabiques de yeso sobre emparrillado de madera, que consideraba menos sólidas e higiénicas. ${ }^{28}$ La posibilidad de contagio de enfermedades entre viviendas adyacentes por el aire infectado pasaba no solo a través de las grietas de forjados y tabiques, sino a través de las tuberías de vapor, agua, gas y electricidad, que no podían aislarse completamente. Para ello, Rafael Guastavino reclamaba evitar la construcción con madera y defendía la bondad de la construcción cohesiva con bóvedas y muros con cámaras intermedias ventiladas que eviten el paso de estos miasmas. ${ }^{29}$

Guastavino no solo conocía y trabajaba sobre el Proyecto del Ensanche de Cerdá, sino que también había leído sus aportaciones escritas, como demostró ya en Estados Unidos en el Congreso Mundial de Arquitectos de Chicago de 1893, cuando tuvo la ocasión de alabar la labor de Ildefonso Cerdá, entre otros referentes de la profesión, a quienes les atribuyó el rol de sostenedores y propagadores de la construcción cohesiva. Además, le nombra específicamente aludiendo al higienismo de sus ideas, añadiendo la necesidad del carácter ignífugo de las construcciones de su propia cosecha:

(...) la arquitectura del paisaje, cuya misión estaría incluida en el lema del eminente ingeniero civil D. IIdefonso Cerdá, en su tratado profundo Teoría de la urbanización: "Urbanizar lo rural y ruralizar lo urbano". Este lema debería ser hoy en día el lema de los departamentos de salud, asumido por los arquitectos de todos los grandes centros de población, con el fin de proteger las condiciones sanitarias de la mayoría frente a las minorías. Los distritos rurales en torno a las grandes ciudades se han de urbanizar para proteger la vida de los habitantes de sus metrópolis; y los distritos urbanos más densos deben retornar a una vida con construcciones y calles higiénicos y a prueba de fuego (...)..$^{30}$

\section{Las fábricas diseñadas por Rafael Guastavino Moreno en Barcelona}

Las fábricas proyectadas por Guastavino se impregnan también, en su especificidad, de la misma filosofía higienista que el maestro de obras aplica a sus edificios de vivienda. Así, por ejemplo, el soterramiento de la sala de tejidos de $7.000 \mathrm{~m}^{2}$ de la fábrica Batlló (1868-1870) (Fig. 2) en su solar y el generoso relleno de mampostería, gravas y tierra en el trasdós de las bóvedas proporciona aislamiento térmico y acústico a los trabajadores.

25 GUASTAVINO, Rafael, 1893a, p. 64-67.

26 GUASTAVINO, Rafael, 1875b, p. 380.

27 GUASTAVINO, Rafael, 1904, p. 175.

28 GUASTAVINO, Rafael, 1885, p. 59ss.

29 GUASTAVINO, Rafael, 1893a, p. 77-81.

30 GUASTAVINO, Rafael, 1893b, p. 15. 
Los 324 lucernarios de esta sala, ubicados en la cúspide de cada una de las cúpulas vaídas que forman la gran sala de tejidos, proporcionan iluminación y ventilación suficiente y homogénea ${ }^{31}$ a este espacio de enormes dimensiones. El enlucido y blanqueado del intradós de estas cúpulas redunda en una mayor claridad aun si cabe.

Las prominentes chimeneas de ventilación que coronan todas estas fábricas, desde la misma fábrica Batlló de $62,5 \mathrm{~m}$ de altura, que posee una tupida red de conductos subterránea que desemboca los humos en su base, ${ }^{32}$ hasta la fábrica Bernard Muntadas, Aparicio y Cía (1874-1879) de 20 m de altura, la fábrica de Ignacio Carreras (1877-1879) y la fábrica de Ramón Florensa (1877-1880), ambas de cerca de $30 \mathrm{~m}$ de altura o la fábrica de Modesto Casademunt (1877-1880) con dos chimeneas gemelas de 22 $m$ de altura, demuestran hasta qué punto Guastavino estaba preocupado por la contaminación del aire urbano con las emanaciones provenientes de las industrias hasta el punto de expedirlas a la mayor cota posible, por encima de la vida cotidiana de sus habitantes. En un escrito, afirmaba la importancia de la envergadura de estas chimeneas industriales: "...estos gases serán luego lanzados por las altas chimeneas de las fábricas a la atmósfera...".33

El edificio de hilados de la fábrica Batlló, denominado popularmente edificio del reloj, se caracterizaba por su amplitud en planta, con seis crujías. Estas dimensiones llevaban al límite las posibilidades de iluminación y ventilación del espacio. Guastavino compensaba este factor derivado del aprovechamiento máximo sustituyendo cualquier muro intermedio con una cuadrícula de pilares de fundición en las cinco alturas, una estructura singular para su época, para no impedir la difusión de la luz y la ventilación cruzada. Como en la sala de tejidos, el enlucido y blanqueado del intradós de las bóvedas también beneficiaba esta difusión de la luz. Los forjados estaban construidos con vigas de madera sobre los pilares de fundición y revoltones muy rebajados con tabiquillos en el trasdós que sostenían el tablero del pavimento de la planta superior. ${ }^{34}$ La cámara de aire intermedia de los forjados contribuía así al aislamiento acústico de la vibración y el fragor de las máquinas de preparación del hilado (primera planta) y las selfactinas (plantas segunda, tercera y cuarta). Las dos torres de las esquinas alojaban sendas escaleras apechinadas de tres tramos, con unas dimensiones generosas que no solo permitían el trasiego de las máquinas y las selfactinas sino también un amplio tiro central hasta las dobles logias superiores para conseguir una ventilación eficaz.

La fábrica Batlló marcaría un antes y un después en la arquitectura industrial de Barcelona en muchos sentidos: estructural, por su empleo de las bóvedas tabicadas combinadas con pilares de fundición; constructivo por la introducción del mortero de cemento a partir del segundo estrato de las bóvedas tabicadas; ${ }^{35}$ distributivo, por su aprovechamiento óptimo del espacio, incluso desplegando en varias plantas de altura la sección de hilados lo cual facilitaba la transmisión de los embarrados; estilístico, por abandonar el neoclasicismo imperante y dar entrada al racionalismo estructural francés y a la visión de la sinceridad moral de los ingleses; ${ }^{36}$ higienista, por la introducción de novedades que pronto se convertirían en rutina para las fábricas de generaciones subsiguientes, como la profusión de lucernarios de iluminación y ventilación, el empleo de bóvedas tabicadas enlucidas y blanqueadas en el intradós para mejorar la iluminación, el fomento de la ventilación cruzada o la generosa dimensión de chimeneas que agruparan todas las emanaciones. ${ }^{37}$

En sus fábricas sucesivas, Guastavino continuaría incidiendo en estos factores, especialmente en la inserción de tragaluces y lucernarios que permitiesen la mejor iluminación y ventilación posible, como se puede observar en las lumbreras en el lomo de las bóvedas de la fábrica de algodón de Bernard Muntadas, Aparicio y Cía (1874-1879) (Fig. 3), las claraboyas cenitales de los almacenes Grau (1877); las troneras con lunetos en los flancos de las bóvedas del taller de Eusebio Castells (1880) o las lucernas de la fábrica de Modesto Casademunt (18771880), que se abrían en bóvedas dobles con cámara intermedia ventilada para una mejor impermeabilización y aislamiento térmico.

En su etapa de Estados Unidos, Guastavino continuó la promoción de su arquitectura industrial hi-

\footnotetext{
31 GRAUS, Ramón; ROSELL, Jaume; ROCA, Antoni, 2008, p. 323.

32 GRAUS, Ramón; ROSELL, Jaume; ROCA, Antoni, 2008, p. 323.

33 GUASTAVINO, Rafael, 1875c, p. 459.

34 GRAUS, Ramón; ROSELL, Jaume; ROCA, Antoni, 2008, p. 328

35 GRAUS, Ramón; ROSELL, Jaume; ROCA, Antoni, 2008, p. 328, 332.

36 GRAUS, Ramón; ROSELL, Jaume; ROCA, Antoni, 2008, p. 333.

37 GRAUS, Ramón; ROSELL, Jaume; ROCA, Antoni, 2008, p. 333.
} 


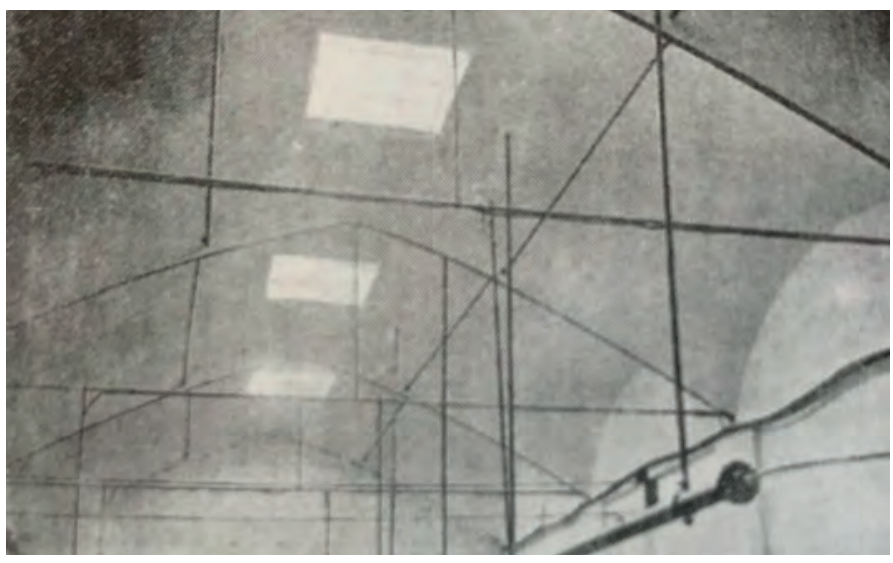

Fig. 3. Probablemente, fábrica Bernard Muntadas, Aparicio y Cía en San Martín de Provençals (1872-76) de Rafael Guastavino Moreno (Avery Library, Columbia University, New York).

gienista como en sus dos prototipos para fábricas ignífugas -una fábrica genérica y una blanquería que afirmaba haber construido ya en Barcelona-, ${ }^{38}$ donde flanqueaba los cerramientos con contrafuertes huecos cada 7,5 m de distancia con una función doble, estructural y estética, que permitían la ventilación continua de los espacios interiores del edificio a través de aberturas en el murete de coronación (Fig. 4). Por otro lado, ofrecía la posibilidad de ventilar la cámara interpuesta entre las bóvedas y el tablero del forjado superior a través de tabiquillos conejeros comunicando esta cámara con los tiros huecos de los contrafuertes en la zona mayor de las enjutas, y de rellenar el trasdós de las bóvedas con cenizas y mortero de cemento natural Rosendale, de producción local, en la zona más estrecha de los lomos de las bóvedas hasta formar el plano de colocación del pavimento superior. El resultado del conjunto era en palabras literales un edificio bien ventilado e iluminado..$^{39}$

En cualquier caso y a diferencia de su etapa profesional en Barcelona, Guastavino no tuvo apenas ocasiones de construir fábricas en Estados Unidos, y sí en cambio multitud de templos, centros docentes y edificios públicos de todo tipo. Siempre que pudo, defendió todas las ventajas de sus bóvedas dobles, denominadas por él bóvedas tubulares o

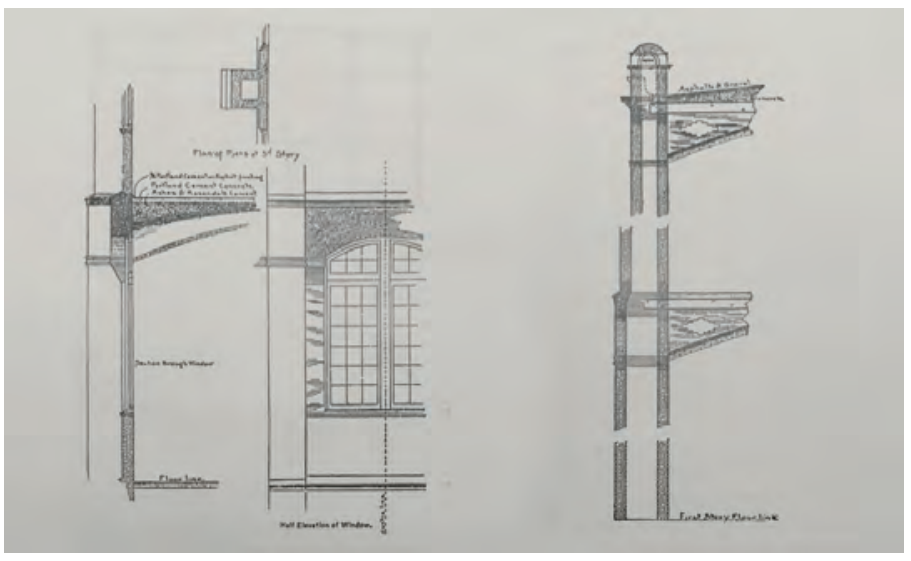

Fig. 4. Secciones y detalles de un proyecto genérico para fábrica ignífuga, donde se observa la ventilación continua del espacio interior a través de contrafuertes huecos abiertos en su coronación, y la alternativa de ventilar la cámara interpuesta entre las bóvedas y el tablero superior o de rellenar el trasdós con cenizas y mortero de cemento natural Rosendale (The American Architect and Building News 22/02/1890).

huecas ("tubular or hollow domes") frente a formas similares en hormigón, que consideraba imposibles de construir con tales dimensiones, resistencia, espesores y rapidez de ejecución. ${ }^{40}$ Las ventajas del aislamiento térmico y acústico, la ventilación, la evitación de las humedades por condensación y la eficaz impermeabilización de las cubiertas dobles, no dejaron indiferentes a los arquitectos estadounidenses de la época.

En el mismo artículo publicado en The American Architect and Building News del 22 de febrero de 1890 , cuyo texto aprovecharía posteriormente para incluirlo con algunas modificaciones en su libro Essay on the theory and history of Cohesive Construction, Guastavino proponía también soluciones para escuelas y colegios universitarios, sin aportar planos, como sí había hecho con sus prototipos de fábricas y viviendas pareadas para obreros. En concreto, recordaba que las formas redondeadas consustanciales a las bóvedas favorecían la buena ventilación según los requisitos dictados por las leyes de la higiene, evitando las esquinas donde se confinaba el aire impuro. Además, defendía las ventajas de la construcción tubular en muros y forjados que brindaba estanqueidad y aislamiento térmico a cada una de las estancias, además de evitar las humedades por condensación. Este carácter al-

38 GUASTAVINO, Rafael, 1875c, p. 459.

39 GUASTAVINO, Rafael, 1890, p. 125.

40 GUASTAVINO, Rafael, 1893b, p. 12-13. 
veolado de muros y forjados permitía evacuar el aire viciado eventualmente acumulado en las esquinas y ventilar completamente las estancias en todas direcciones, sin los inconvenientes de abrir repetidos brochales en los forjados para dar paso a los conductos de ventilación. ${ }^{41}$

\section{La propuesta de mejora de la salubridad para las ciudades industriales (1876)}

Rafael Guastavino Moreno presentó a concurso en la Exposición del Centenario de Filadelfia de 1876 una propuesta titulada "Improving the Healthfulness of Industrial Towns" que recibió una distinción en el certamen. Su contenido nos era desconocido hasta hoy en día y, como se verá, había sido incorrectamente identificado con su proyecto para casa obrera ignífuga erigida con el sistema cohesivo de 1889 . Solo se tenía referencia de esta propuesta presentada en Filadelfia a través del artículo publicado en The American Architect and Building News del 22 de febrero de 1890, donde Guastavino enlazaba la descripción de sus muros y forjados alveolados con las ideas presentadas a la Exposición de Filadelfia catorce años antes. En esta propuesta, Guastavino proponía insertar en muros y forjados canalizaciones de ventilación del aire viciado de las habitaciones, en particular, el acumulado en las esquinas, a comunicar con la base del hogar de chimeneas y fogones con el objetivo de "quemar" el aire contaminado en las llamas.

Recientemente, el investigador Benet Oliva ${ }^{42}$ ha localizado una serie de cinco artículos escritos por Rafael Guastavino bajo el título "Estudios sobre higiene urbana", publicados en Barcelona en la revista El porvenir de la industria. Periódico semanal de Ciencias, Industria, Agricultura y Comercio en el año 1875, que se corresponden en título y contenido con la propuesta presentada en inglés un año después en el certamen de Filadelfia de 1876. Este sorprendente texto por entregas ofrece una nueva faceta de este maestro de obras, ya de por sí versátil y poliédrico: la de un experto en química. Guastavino apoyaba sus tesis citando a científicos acreditados como Guillaume Dupuytren (1777-1835), autor del Diccionario de ciencias médicas por una sociedad de los más celebres profesores de Europa
(1821), o a M. J. Girardin (1803-1884), autor de Lecciones de química elemental (1841), y demostraba estar al día de las últimas innovaciones la materia, en particular, en Francia, o al químico también francés Jean-Pierre-Joseph d'Arcet (1777-1844).

En efecto, el primer artículo estaba dedicado a describir la química de las emanaciones deletéreas presentes en Barcelona y otras ciudades similares. ${ }^{43} \mathrm{El}$ acento del texto no estaba depositado en la contaminación derivada de la industria, como cabría pensar desde nuestra perspectiva contemporánea, sino más bien en las emanaciones sulfhídricas y amoniacales provenientes de las letrinas, el alcantarillado y la descomposición en general de las sustancias orgánicas. Guastavino demostraba conocer y manejar con soltura la composición química de estos miasmas: ácido sulfhídrico, ácido carbónico, óxido de carbono, amoníaco, y cómo la presencia combinada del amoníaco y el hidrógeno sulfurado generan sulfhidrato de amoníaco, que se descomponía fácilmente por su inestabilidad. El artículo se extendía en múltiples detalles de la concentración exacta que se requería en la atmósfera para matar a un perro, un caballo o un ser humano y de cómo estos productos podían generar fácilmente ácido sulfúrico, ácido sulfuroso, azufre, óxido de amonio, etc. El segundo artículo de la serie enlazaba los gases mefíticos descritos con los sistemas antaño existentes para evitar su propagación y en particular su disolución en el suministro de agua para consumo o limpieza de alimentos, desde la trapa y el sifón, hasta el empleo de agentes químicos como el hipoclorito de cal, el sulfato de zinc, etc., cuyo uso no se había generalizado por su coste y dificultad de mantenimiento y la ventilación, expeliendo a la atmósfera a la mayor altura posible estos gases perniciosos. ${ }^{44} \mathrm{El}$ tercer artículo de la serie describía su sistema para desinfectar o eliminar las emanaciones perniciosas de las letrinas y del alcantarillado de la ciudad haciéndolas circular por canalizaciones a través de los hogares de las viviendas y los hornos de las calderas industriales de la ciudad, respectivamente. ${ }^{45}$ Guastavino conocía bien el sistema de alcantarillado porque incluso reseñaba la construcción de las cloacas de Valencia en cal y canto a pesar de que la región era rica en arcilla. ${ }^{46} \mathrm{El}$ cuarto artículo por

\footnotetext{
41 GUASTAVINO, Rafael, 1890, p. 126.

42 A quien agradecemos enormemente la noticia proporcionada.

43 GUASTAVINO, Rafael, 1875a, p. 347.

44 GUASTAVINO, Rafael, 1875b.

45 GUASTAVINO, Rafael, $1875 \mathrm{c}$.

${ }^{46}$ GUASTAVINO, Rafael, 1893a, p. 12.
} 
entregas especificaba en detalle la descomposición química de sustancias químicas inorgánicas antes mentadas bajo el efecto de la llama. ${ }^{47} \mathrm{Y}$ el quinto artículo explicaba la descomposición de las materias orgánicas que son causa de infección y enfermedades, y muestra la economía y las ventajas de la instalación de este sistema. ${ }^{48}$

En estos cinco artículos Guastavino nombraba ejemplos eficaces de ventilación, como el hospital Lariboisiere ${ }^{49}$ de mujeres en París, diseñado por el arquitecto Martin-Pierre Gauthier (1790-1855), construido entre 1846 y 1853 y hoy todavía activo, donde los retretes de elevados techos ejercían un tiro enérgico sobre el foso con el resultado de una ventilación constante y poderosa, que se podía forzar o acentuar con un hornillo encendido de servicio. O el hospital de Sant Louis ${ }^{50}$ (1607), también en París, impulsado por el rey Enrique IV y diseñado por Claude Vellefaux (i?-1629), donde el químico d'Arcet había insertado en medio del canal una luz de mecha que servía simultáneamente para iluminar y para forzar el tiro de ventilación. O la prisión de Mazas, ${ }^{51}$ también en París, diseñada y construida por el arquitecto Émile Gilbert (17931874) entre 1845 y 1850 y destruida en 1898, un panóptico diseñado según los principios higienistas más avanzados de la época, donde el asiento de las letrinas individuales de cada preso tenía aberturas que aspiraban hacia abajo el aire de la celda hacia una gran chimenea de ventilación. Guastavino alababa estos sistemas de ventilación por procurar la higiene del edificio aunque tenían el inconveniente de que las emanaciones se transmitían a la atmósfera en todo caso. ${ }^{52}$

Las menciones de estos edificios de París, además de otras referencias en su obra construida a las escaleras metálicas, la composición de las fachadas del ensanche, o la inserción de miradores en es- quina, permiten sospechar que había visitado esta ciudad. Guastavino pasó con bastante probabilidad por París en su camino a Le Havre para embarcar en el buque Ville de Marseille que le llevaría a Nueva York en 1881. Pero ¿había visitado la ciudad antes? Su primo hermano Climent Pujol i Guastavino (1853-i1910?), hijo de su tía Antonia Guastavino Buch, que había nacido en Olesa de Montserrat y había estudiado en la Escuela de BeIlas Artes de Barcelona, ${ }^{53}$ residía alli ${ }^{54}$ al menos desde $1876,{ }^{55}$ y consta que se mantuvo en contacto con su familia española. ${ }^{56}$

En cualquier caso, si Rafael Guastavino Moreno no visitó París antes de emigrar a Estados Unidos en 1881, al menos, sí estaba informado de los últimos avances, novedades y nuevos edificios que se estaban erigiendo en la ciudad. La referencia a los hospitales de París puede haber derivado de una visita a los edificios, pero también haber sido extraída, al menos, parcialmente, del artículo "Étude de la Construction des Établissements Hospitaliers", escrito por el arquitecto e ingeniero Émile Lavezzari (1832-1887) y publicado en la Revue de I'Architecture et des Travaux Publics en 1864, donde colaboraba habitualmente. ${ }^{57}$ Esta conocida revista, fundada y dirigida por el arquitecto César Daly (1811-1894) entre 1840 y 1888, foro y eje vertebrador de innumerables debates e iniciativas arquitectónicas en el siglo XIX, se caracterizó también por la frecuencia con la que se trataban en sus páginas las cuestiones higienistas, en sintonía con la inquietud y el espíritu de los tiempos.

La preocupación de la ventilación de las estancias de los hospitales, ligada a su calefacción, generó artículos con una cierta frecuencia en el último cuarto del siglo XIX, con estudios de las corrientes de aire naturales e inducidas en aras a conseguir

47 GUASTAVINO, Rafael, 1875d.

48 GUASTAVINO, Rafael, $1875 \mathrm{e}$.

49 GUASTAVINO, Rafael, 1875b, p. 381.

${ }^{50}$ GUASTAVINO, Rafael, 1875b, p. 381.

${ }^{51}$ GUASTAVINO, Rafael, 1875b, p. 382.

52 GUASTAVINO, Rafael, 1875b, p. 383.

53 VEGAS, Fernando; MILETO, Camilla; CANTERO, Víctor Manuel, 2017, p. 227.

${ }^{54}$ Poseía su vivienda y taller en rue Boissonade 11 del barrio de Montparnasse.

55 FLAQUER, Silvia, 1986, p. 313.

${ }^{56}$ En el año 1878 el primogénito del arquitecto Rafael Guastavino Moreno, José Guastavino Guastavino, presentó los planos de una bodega a la Exposición Universal de París (LASHERAS PEÑA, 2009, p. 1284), el mismo certamen en que Climent expuso el lienzo Le contrat de mariage. Años más tarde, en 1908, tras varios años en París y siguiendo los pasos de su hijo mayor José Ramón que en 1905 ya había embarcado rumbo a Nueva York para trabajar en la empresa de su tío, Juana Guastavino Moreno, la hermana de Rafael, zarpó desde Cherburgo hacia Nueva York con sus hijos.

${ }^{57}$ LAVEZZARI, Émile, 1864, p. 180-205. 
la renovación del aire con gérmenes del interior. ${ }^{58}$ La obsesión por respirar aire puro, especialmente durante el reposo nocturno, llegó a generar soluciones como las camas donde la cabecera se proyectaba en voladizo fuera de la ventana mientras que el cuerpo quedaba abrigado dentro, bajo las mantas. En Estados Unidos, en 1850, Harriet Martineau escribió un artículo burlón para la revista Harper's Monthly en el que daba instrucciones al lector para crear un dormitorio insalubre. Entre las instrucciones, se recogía: "...cierra la chimenea de modo que el aire viciado no pueda escapar durante la noche; igualmente, cierra la ventana...".59 La respiración de aire puro y la ventilación de los dormitorios era también una de las recomendaciones del gran sacerdote de la naturopatía, Sebastian Kneipp (1821-1897), cuya filosofía, basada en la hidroterapia entre otros tratamientos naturales, ${ }^{60}$ fue adoptada años después por Antoni Gaudí. ${ }^{61}$ Guastavino debe haberse familiarizado con la cura por hidroterapia de este reverendo alemán en su propuesta de balneario en las aguas termales del Monasterio de Piedra para Juan Federico Muntadas (1826-1912), que no llegó a buen término por razones desconocidas. ${ }^{62}$

Por otra parte, la inquietud en torno a la evacuación eficaz de las aguas fecales era compartida a nivel internacional. Incluso en Estados Unidos, a pesar de su menor densidad de población, la transición entre el excremento entendido como fertilizante a desecho a evacuar por las alcantarillas tuvo lugar de manera abrupta. ${ }^{63}$ El movimiento estadounidense denominado City Beautiful, concebido por Charles Mulford Robinson (1869-1917) en paralelo con la obra de Guastavino y al que tanto contribuyó con sus grandiosas bóvedas y cúpulas, no solo se basaba en el embellecimiento por monumentalización de las ciudades, sino también en la resolución de los problemas de hacinamiento y contaminación con una filosofía higienista traducida en la salubridad urbana. ${ }^{64}$

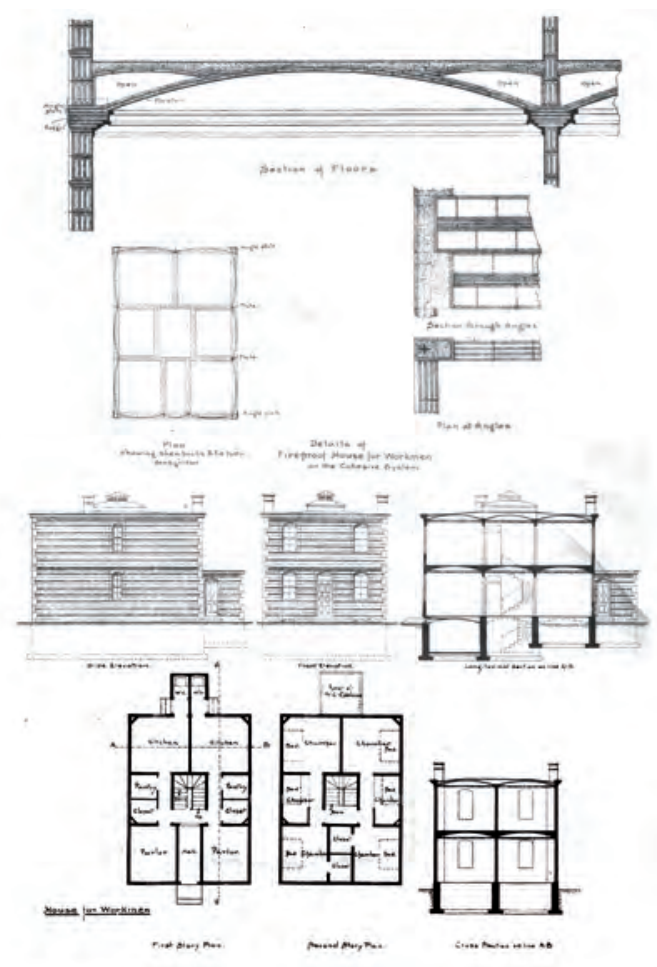

Fig. 5. Proyecto de casa obrera ignífuga, que reúne muchas de las propuestas constructivas e higiniestas de Rafael Guastavino Moreno (The American Architect and Building News 22/02/ 1890).

\section{El proyecto de casa obrera ignífuga erigida con el sistema cohesivo (1889)}

En esta propuesta para una casa obrera ignífuga (Fig. 5), que ha sido erróneamente identificada como la presentada a la Exposición de Filadelfia de $1876,{ }^{65}$ bautizó la solución de muros y forjados

\footnotetext{
58 BANHAM, Reyner, 1975, p. 48-55.

59 MARTINEAU, Harriet, 1850, p. 618-619.

60 KNEIPP, Sebastián, 1889, p. 50ss.

61 BASSEGODA, Juan, 1989, p. 17.

62 GUASTAVINO, Rafael, 2006b, p. 4.

63 GERLING, Daniel Max, 2012, p. 25ss.

64 ROBINSON, Charles, 1901.
}

65 A diferencia de lo expuesto por Jaume Rosell Colomina (1995), que se basa en el artículo titulado "Cohesive construction" publicado por Rafael Guastavino el 22 de febrero de 1890 en la revista The American Architect and Building News vol. XXVII, $\mathrm{n}^{\circ} 739$, February 22, 1890, p. 123-126, texto de la conferencia dictada en el Thursday Club de Boston el 2 de enero de 1890 , a su vez ya dictada parcialmente, planos incluidos, en la Society of Arts del Massachusetts Institute of Technology el 24 de octubre de 1889, se estima que esta propuesta denominada Fireproof House for Workmen on the Cohesive System se preparó probablemente para esta publicación y no para la Exposición de Filadelfia de 1876, como el mismo Rafael Guastavino parece 
alveolados como construcción tubular, por las celdillas y cámaras de aire que recorrían longitudinalmente tanto en horizontal como en vertical estos elementos arquitectónicos, de manera que todos los rincones de cualquier habitación pudieran estar bien ventilados en cualquier dirección. ${ }^{66}$ Posteriormente, en 1904, Guastavino afirmaría en la parte II de su libro The Function of Masonry in Modern Architectural Structures que el Art Nouveau con sus curvas y transiciones suaves es beneficioso para la higiene de la casa, porque evitaba la acumulación de aire viciado. ${ }^{67}$

El proyecto de Guastavino consistía en un pequeño edificio exento iluminado en los cuatro frentes de dos casas pareadas distribuidas con una escalera central común de distribución. Cada vivienda poseía un sótano de almacén, planta baja con vestíbulo de entrada, ropero, estar, cocina, despensa y retrete, y planta superior vestíbulo y tres dormitorios, uno de ellos con vestidor incorporado. El sótano aparecía únicamente en la primera crujía, bajo los salones y el vestíbulo de entrada, pero se dejaba abierta la posibilidad de su ampliación futura en la crujía central y la posterior, a juzgar por la disposición de los muros de contención y la profundidad de las zapatas de cimentación. Los forjados estaban construidos con cúpulas vaídas tabicadas de rasilla cubriendo cada habitación atirantadas con barras de $6 \mathrm{~mm}$ de diámetro (1/4 de pulgada) absorbidas en la tabiquería contenidas en la fachada exterior por siete placas simples y cuatro placas angulares en esquina. Guastavino decide ampliar los revoltones entre las viguetas de madera o metálicas ya de por sí inusualmente amplios diseñados por él, al menos en el edificio de hilaturas de la fábrica Batlló (186870), la Casa Montalt (1871), en la Casa Blajot (1871), extenderlos hasta cubrir una habitación completa y eliminar las viguetas de apoyo y sustituirlas por las paredes de la habitación, con la ayuda de tirantes estructurales. Guastavino recomendaba el empleo de las cúpulas en las casas privadas por ser más económicas, decorativas y resistentes que las bóvedas de cañón, ${ }^{68}$ además de suavizar los encuentros y eliminar más rincones donde se podría acumular el ai- re viciado. ${ }^{69}$ Los muros de cerramiento y distribución estaban constituidos por fábricas de ladrillo cerámico alveolado con pilarcillos integrados en las esquinas y encuentros de la tabiquería de distribución con el perímetro del edificio. Estos pilarcillos estaban formados por cuatro perfiles angulares en L en disposición cruciforme que servían de conexión vertical de los tirantes. Los pilarcillos de esquina aparecían embebidos en un relleno de hormigón de cemento vertido en sillares huecos prefabricados de cerámica o cemento trabados en adaraja en las esquinas con la fábrica cerámica adyacente cada dos hiladas de la misma. ${ }^{70}$ El tratamiento exterior de fachada se caracterizaba por un aplacado listado con molduras cerámicas horizontales cada dos hiladas. Todas las estancias interiores poseían una imposta o moldura perimetral en el arranque de las cúpulas vaídas formada con yeso sobre una base escalonada ya perfilada por rasillas cerámicas de diversa longitud. Los interiores estaban enlucidos con yeso, tanto en bóvedas como en paramentos, lo que redundaba en una mayor claridad.

Más allá de la perplejidad que expresó Ruf en 2007 frente a su verdadero funcionamiento estructural, aspecto que no compete a este artículo analizar, cabe señalar algunos aspectos interesantes en esta propuesta desde el punto de vista del higienismo:

-Se observa, tal como se ha señalado en sus edificios de vivienda en el Ensanche, una separación entre la cocina y el retrete mediante una doble puerta y el vestíbulo de acceso al jardín trasero.

-Se señala también la existencia de un sótano bajo rasante con tragaluces alunetados en la fachada principal, que evita las humedades a la planta baja, además de ampliar la superficie de la vivienda.

- La escalera central posee iluminación y ventilación cenital, además de la luz aportada por el montante acristalado o claristorio sobre el portal de acceso. Esta escalera se constituye también en tiro de ventilación cruzada para las viviendas a través de los claristorios sobre las cuatro puertas de acceso (dos en la zona de día en planta baja y dos en la zona de

indicar en su texto cuando remite de manera externa a las propuestas presentadas a la propuesta titulada Improving the Healthfulness of Industrial Towns, que incluía texto (aparentemente identificado en este artículo más adelante) y planos (desconocidos, mientras no se demuestre lo contrario). Además, también explica "these plans (...) are the result of twenty years' experience (...)". Si se hubieran realizado en 1876, estos veinte años habrían implicado el inicio de su andadura profesional en 1856 , con catorce años.

${ }^{66}$ GUASTAVINO, Rafael, 1890, p. 126.

67 GUASTAVINO, Rafael, 1904, p. 153.

68 GUASTAVINO, Rafael, 1893a, p. 78-79.

69 GUASTAVINO, Rafael, 1890, p. 126.

70 GUASTAVINO, Rafael, 1890, Lám. Fireproof House for Workmen. 
noche en planta $1^{a}$ ), que también permiten iluminar los vestíbulos de entrada con la claridad aportada por la claraboya de la escalera.

-Se ubican los tiros de las chimeneas del fogón en la cocina y del salón matando las esquinas con un pequeño chaflán en ambos casos de modo que, según sus propias ideas, ${ }^{71}$ se evitaba la acumulación de aire viciado en los ángulos de las habitaciones.

-Los cerramientos están construidos con bloques cerámicos perforados compuestos de 4 rasillas cada uno, con 3 pequeñas cámaras de aire entre ellas que se comunican con las adyacentes, una suerte de bloque de termoarcilla avant la lettre. En su descripción: "The outside walls are built of blocks of tile, each block containing six tiles with air-spaces between them (...)" ${ }^{\prime 72}$ El cerramiento así construido equivaldría a 4 tabiques de rasillas colocados a panderete separados por 3 cámaras de aire intermedias de aislamiento. Los muros de separación entre viviendas también están constituidos por bloques cerámicos similares pero más estrechos, equivalentes a tres tabiques de rasillas colocados a panderete separados por dos cámaras de aire intermedias de aislamiento.

-El trasdós de las bóvedas no se rellena con masa alguna, sino que se deja en gran parte vacío encaballando pequeñas bóvedas tabicadas en las enjutas para acercarse al plano horizontal del pavimento o el tablero inclinado de cubierta, generando bóvedas dobles que redundan en un mayor aislamiento acústico, térmico e hídrico entre forjados.

-Estos muros y forjados tubulares permitirían la instalación de un sistema de tuberías que conecta "cada esquina de la habitación con la estufa o el hogar de calderas, fogones u hornos, con el fin de que pase a través de las llamas, que es una buena manera de transformar el aire impuro", ${ }^{73}$ siempre acumulado en las esquinas de las habitaciones.

Esta propuesta adquiere gran trascendencia desde el momento en que Rafael Guastavino Moreno confesó en varios de sus textos que el diseño de su residencia personal (1872-1875) en la confluencia de las calles Aragón y Lauria (Fig. 6) en BarceIona fue una experiencia de materialización de

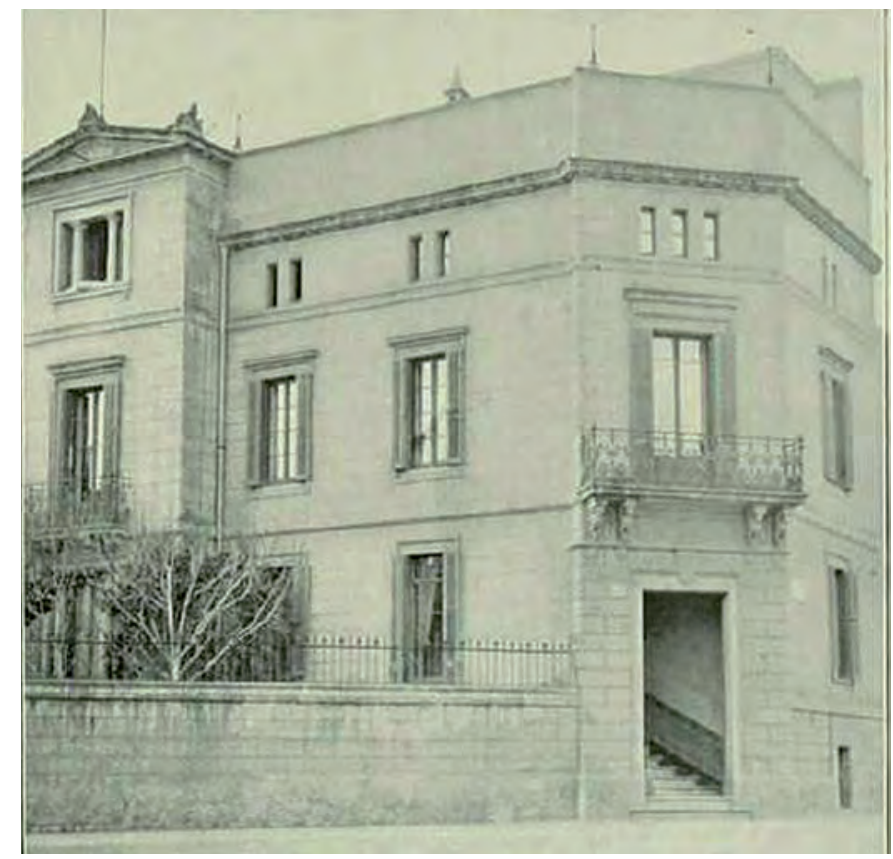

Fig. 6. Casa propia de Rafael Guastavino Moreno en la confluencia de las calles Aragón y Lauria de Barcelona, donde el arquitecto aplicó sus ideas a modo de ensayo en propias carnes (Wight 1901a).

sus ideas, como el médico que probara su medicina en sus propias carnes. ${ }^{74}$ En efecto, allí ensayó las siguientes soluciones:

-La construcción de forjados con cúpulas vaídas huecas, prácticamente sin vigas, a cuatro alturas, ${ }^{75}$ de bóveda tabicada, tabiquillos o contrabóvedas en el trasdós y tablero superior de pavimento como había realizado previamente en el edificio de hilaturas de la fábrica Batlló (1868-1870). ${ }^{76}$

-El empleo primerizo del cemento Portland que se hizo importar de Inglaterra, ${ }^{77}$ para posteriormente pasar a pilotar la producción de un cemento Portland español en hornos de carga discontinua, asesorando al industrial republicano Rafael Montestruc Mored (1826-1891). ${ }^{78}$

\footnotetext{
71 GUASTAVINO, Rafael, 1890, p. 126.

72 GUASTAVINO, Rafael, 1890, p. 126.

73 GUASTAVINO, Rafael, 1893a, p. 67, 171.

74 GUASTAVINO, Rafael, 1893a, p. 5.

75 GUASTAVINO, Rafael, 1890, p. 125.

76 GRAUS, Ramón; ROSELL, Jaume; ROCA, Antoni, 2008, p. 38.

77 WIGHT, Peter Bonnett, 1901a, p. 80.

78 WIGHT, Peter Bonnett, 1901a, p. 80; VEGAS, Fernando; MILETO, Camilla; CANTERO, Víctor Manuel, 2017, p. 224.
} 
-El diseño de una escalera helicoidal en bóveda tabicada ${ }^{79}$ a diferencia de sus escaleras domésticas previas nobles de estructura metálica y peldaños de mármol, como el Palacete Oliver (1869-1870), la Casa Blajot (1871) (Fig. 1) y presumiblemente la Casa Juliá (1871) y la Casa Anglada (1873). ${ }^{80}$

-De la única fotografía existente de la casa y de la ubicación de la misma dentro del solar, se pueden deducir también otros puntos en común con la propuesta para la casa obrera ignífuga, como la existencia de un semisótano iluminado y ventilado por tragaluces alunetados en las bóvedas tabicadas; la presencia de una claraboya de iluminación y ventilación sobre la escalera de distribución; y el recurso a un despiece de fachada con un módulo mayor del ladrillo de la fábrica. No se puede afirmar con certeza el empleo de muros de ladrillo alveolado o con cámara de aire, como tampoco la existencia de placas de contención de los tirantes de los forjados, que podrían haberse alojado en las cornisas corridas de fachada que marcan los niveles internos de cada forjado.

Terminado este experimento en su propia casa en 1875, Guastavino habría estado en posición de exponer sus ideas tanto por escrito en su colección de cinco artículos en la revista El porvenir de la Industria, invención razonada que enviaría, junto con 21 fotografías de sus obras construidas en Barcelona, a participar en el certamen de la Exposición de Filadelfia de 1876.

\section{Los cerramientos con cámara de aire}

La promoción activa de los cerramientos de doble hoja ${ }^{81}$ o los cerramientos de ladrillos formados por varias rasillas con cámaras de aire intermedias ${ }^{82}$ por parte de Rafael Guastavino, al menos desde esta propuesta que data de 1889, no debe pasar desapercibida. Lo que hoy se considera una rutina constructiva era entonces una gran novedad constructiva, todavía por asumir. Las primeras referencias a cerramientos de doble hoja de ladrillo con una cámara intermedia surgen en la primera década del siglo XIX en el Reino Unido, derivadas de la voluntad de ahorrar materiales, incrementar la estabilidad estructural y mejorar el aislamiento térmico, a las que se añadió a mediados de la década de 1820 la prevención frente a la entrada del agua de lluvia. En cualquier caso, durante todo el siglo XIX se debatió sobre el origen de la humedad en los muros -si derivaba de la condensación o de la penetración del agua de lluvia- y sobre la bondad eventual de ventilar la cámara intermedia. Las dos hojas de estos primeros cerramientos se aparejaban con perpiaños intermedios que atravesaban la cámara de aire, en forma de ladrillos a tizón o llaves de gres, hierro forjado o fundición. Aunque este tipo de muros dobles se nombró durante el siglo XIX en diversos tratados ${ }^{83}$ y se empleó ocasionalmente en algunas experiencias, no fue hasta después de la Primera Guerra Mundial que se impuso progresivamente como rutina en la construcción. ${ }^{84}$

En España, ninguno de los manuales o tratados de construcción decimonónicos más conocidos como Villanueva (1827), Matallana (1848), Fornés y Gurrea (1857), Marcos y Bausá (1879) aludieron a esta posibilidad y expusieron solo diversas variantes de aparejo para muros macizos. El breviario de Espinosa (1859) sí mostró algunos aparejos con huecos internos, pero nombró expresamente su macizado o relleno posterior con cascotes. Fue necesario esperar hasta el compendio de Ger y Lóbez ${ }^{85}$ (1898), para encontrar un capítulo sobre "Paredes o tabiques sordos o abrigados", esto es muros dobles con cámara intermedia que permitían aislar del sonido, el calor, el frío y la humedad. En cualquier caso, este tipo de muros con cámara intermedia no se empezó a aplicar en España hasta la década de 1920.86

Dentro de ese panorama, Rafael Guastavino Moreno parece ser, sino el primero, uno de los primeros promotores españoles de los muros con cámara de aire intermedia con su propuesta fechada en 1889. Rafael Guastavino demostró de nuevo estar muy al día de lo que se está publicando e investigando en el extranjero, especialmente en el Reino Unido, donde esta solución constructiva era objeto

79 GUASTAVINO, Rafael, 2006b, p. 7: “...in his elegant four-story town house in Barcelona with its impressive marble entrance hall and circular staircase..." En su nueva casa, donde el objetivo era eliminar las estructuras metálicas expuestas, no habría tenido sentido emplear la fundición.

80 LUENGO PÉREZ, Noelia, 2016.

81 GUASTAVINO, Rafael, 1893a, p. 65-67, 81.

82 GUASTAVINO, Rafael, 1890, p. 126.

83 GWILT, Joseph, 1859; GWILT, Joseph, 1888; ADAMS, Henry, 1906.

84 HENRY, Alison et. al., 2015, p. 444-445.

85 GER Y LÓBEZ, Florencio, 1898, I, p. 191; GER Y LÓBEZ, Florencio, 1898, II, Lám.VI.

${ }^{86}$ ROS, Juan Manuel, 2005, p. 60 
de mayor estudio y debate. En cualquier caso, no le debió resultar muy difícil imaginar las ventajas de la interposición de cámaras de aire en los muros de cerramiento, considerando la tradición local de construir bóvedas tabicadas dobles con cámara intermedia separadas por lengüetas o tabiquillos en sustitución de los rellenos en el trasdós, existente desde finales del siglo XV. ${ }^{87}$ Se trataba únicamente de abstraer y aplicar las ventajas obtenidas en el plano horizontal al plano vertical. Además, Guastavino atribuía a la bóveda hueca o bóveda doble con separadores intermedios una mayor resistencia estructural por su aumento del momento de inercia o radio de giro del mismo modo que si fuera una cercha estructural. ${ }^{88}$

\section{La reforma interior de la ciudad de Valencia propuesta por Carlos Guastavino Moreno}

Mientras Rafael Guastavino Moreno cosechaba sus primeros éxitos en Estados Unidos, en Valencia, su hermano menor Carlos Guastavino Moreno (1851¿?), fue protagonista de una interesante iniciativa de reforma higiénica de la ciudad que revelaba su relación con las ideas de Rafael. ${ }^{89}$ En 1888, el Ayuntamiento de Valencia lanzó un concurso de mejoras urbanas y reforma interior del centro ${ }^{90}$ en el que ocho sociedades y particulares presentaron sus propuestas: la Sociedad Constructora Valencia, la Junta de Escuela de Artesanos, Arturo Martín, A.J. \& Cía, Carlos Guastavino, la Sociedad de Maestros Carpinteros, la Liga de Propietarios de Valencia y el Instituto Médico Valenciano. La mayoría de estas propuestas se centró en la circulación y articulación entre centro histórico y el ensanche y en la ampliación y realineación de calles y plazas. Pero el único que abordó de manera directa, consciente y casi exclusiva el higienismo fue Carlos Guastavino.

A juzgar por los términos empleados por Carlos Guastavino, puede presumirse que conocía tanto el Reglamento de Policía Urbana de 1844 como la Memoria del Proyecto del Ensanche de 1858, que incidían en la problemática de la vivienda en los mismos términos. Ante la ausencia de formación reglada en aspectos técnico-teóricos de urbanismo de Carlos manifestada por él mismo, llama la atención su inquietud y quizás pueda aventurarse el intercambio de información entre los hermanos Carlos y Rafael Guastavino a juzgar por sus inquietudes paralelas, o una actitud de seguimiento del hermano menor, diez años más joven y sin estudios, hacia el mayor, un profesional de prestigio internacional, cuyas proezas en Estados Unidos comenzaban a aparecer en la prensa local. Carlos proponía cuatro medidas para conjurar el problema de salubridad: la evitación de la humedad del suelo y las habitaciones; el saneamiento de los pozos, la limpieza del sistema de retretes y la construcción y limpieza de las alcantarillas. ${ }^{91}$ Frente a las humedades, Carlos sugería como posible solución que en plantas bajas donde hubiera dormitorios los suelos estuvieran separados del terreno natural al menos un metro y que este espacio estuviera ventilado por dos o más orificios opuestos. Además de estar construidas con cal hidráulica, las paredes debían estar enlucidas exterior e interiormente con cemento hasta sesenta centímetros sobre el nivel del suelo. Estas modificaciones junto al ensanche de las calles de la ciudad permitirían al sol y al aire ejercer toda su influencia beneficiosa. Para superar la insalubridad de los pozos que generaban el aire nocivo, Carlos Guastavino planteaba tapiar los orificios de los pozos e instalar bombas de evacuación para alejar los gases mefíticos de las viviendas. Además, Carlos aconsejaba sustituir los retretes, "engendradores de la peste", por un sistema de válvula a tiro de agua de fácil aplicación, instalando bombas y depósitos en los pisos donde no hubiera suministro de agua, obteniendo la limpieza de los hogares y de los conductos. Añadía también que el problema del alcantarillado era la falta de un enfoscado de cemento que impidiera las filtraciones perniciosas a los pozos de suministro y recomendaba: "darle forma semicilíndrica, enfoscar con cemento su base e impedir la acumulación de materias fecales en el interior del edificio, construyendo frente a cada casa bajo las aceras depósitos inodoros de hierro para recogerlas". ${ }^{92}$

\footnotetext{
87 ZARAGOZÁ, Arturo; VEGAS, Fernando, 2019, p. 21-22.

88 GUASTAVINO, Rafael, 1893a, p. 65.

89 Carlos Guastavino Moreno fue el octavo de los catorce hijos que tuvieron Rafael Guastavino Buch y Pascuala Moreno Ebrí. Nació en Valencia un 26-07-1851 en la calle Verónica $n^{\circ} 7$ bajo. En el contiguo número 9, su padre Rafael tenía el taller de ebanistería donde tanto Rafael como Carlos y otros hermanos se formaron. Asistió junto a sus hermanos a una escuela situada entonces en la calle Ancha de la Platería (hoy Numancia) dirigida por el maestro Mariano Aser Yranzo. En 1869 Carlos y su hermano Manuel fueron nombrados maestros del gremio de carpinteros de Valencia. En 1875 se casó con Jeanne Marie Pecenot en Marsella. Años más tarde, enviudó y volvió a contraer nupcias allí con Francisca Boyer, de cuyo enlace nació, ya en Valencia, Carlota Guastavino Boyer el 02-12-1888, ocho meses después de haber vuelto a la ciudad.

90 AHMV. Policía Urbana, 1889, Caja 173bis, Exp. 43, Proyecto de reforma interior.

91 AHMV. Policía Urbana, 1889, Caja 173bis, Exp. 43, Proyecto de reforma interior. Propuesta de Carlos Guastavino.

92 AHMV. Policía Urbana, 1889, Caja 173bis, Exp. 43, Proyecto de reforma interior. Propuesta de Carlos Guastavino.
} 
Resultan Ilamativas algunas propuestas por su similitud con las ideas y la obra construida de Rafael Guastavino, como la elevación de las plantas bajas respecto al terreno; la bondad de la ventilación cruzada; el empleo de mortero de cemento en el enlucido de zócalos para combatir la humedad por capilaridad y en el enfoscado de pozos y alcantarillados para evitar las filtraciones hacia los pozos de abastecimiento de agua; y la mención similar al aire impuro generado por los pozos de aguas fecales. No se conoce la intensidad del contacto entre ambos hermanos, pero sí se puede adivinar un cierto ascendente de las ideas del flamante hermano mayor, Rafael, en el hermano pequeño, Carlos.

\section{Conclusiones}

El maestro de obras Rafael Guastavino es conocido fundamentalmente por sus obras diseñadas o construidas con bóveda tabicada, pero su legado va más allá de esta técnica. Guastavino vivió y desarrolló su profesión principalmente en la segunda mitad del siglo XIX, que Reyner Banham definió como "un siglo oscuro y satánico" debido a las condiciones de vida y de trabajo, la proliferación de la infravivienda, el asoleamiento y ventilación deficitarios y la contaminación urbana derivada del humo y los efluvios de alcantarillas y restos orgánicos, ${ }^{93}$ y fue testigo de excepción del surgimiento de los ensanches en la ciudad de Valencia y Barcelona que venían a paliar esta situación. Tanto su obra construida en el ensanche barcelonés como sus escritos demuestran un prurito especial por la mejora de las condiciones de salubridad, un aspecto que hasta ahora había pasado desapercibido a la bibliografía. Cabe señalar sobre todo la propuesta revolucionaria en el hasta ahora desconocido artículo denominado "Estudios sobre la higiene urbana", galardonado en la Exposición de Filadelfia de 1876, que revela su condición paralela de experto en química. Emigrado a Estados Unidos, continuó promoviendo su construcción cohesiva ya que podía brindar a los arquitectos, entre otras muchas ventajas, mejores condiciones higiénicas que las estructuras metálicas e incluso que las incipientes de hormigón. ${ }^{94}$ Su proyecto de casa obrera ignífuga erigida con el sistema cohesivo (1889), antes erróneamente datada en 1876, propuso cerramientos con cámara de aire, esquinas romas y bóvedas vaídas alveoladas por el trasdós, con el fin de evitar la acumulación del aire viciado y su correcta ventilación, además de mejorar el aislamiento térmico, acústico y de la humedad. Es interesante se- ñalar que, con su promoción de las formas redondeadas, los encuentros suavizados y las bóvedas tabicadas, el propio Guastavino, referente para la siguiente generación de arquitectos catalanes, fomentó de manera involuntaria las formas curvas que caracterizarían al Modernismo, corriente artística que él mismo llegó a aplaudir en vida. Además, sus ideas higienistas también encontraron eco de vuelta en su Valencia natal a través de la propuesta que su hermano Carlos Guastavino presentó para la mejora de la salubridad y la reforma interior.

\section{Bibliografía}

ADAMS, Henry. Adams' Building Construction. London: Routledge, 1906. Citado por HENRY, Alison, 2015.

Archivo Histórico Municipal de Valencia (AHMV). Certificado de defunción de $\mathrm{M}^{\mathrm{a}}$ Josefa Ebrí Nadal. 1854. Valencia, Registro Civil de Defunciones por casos del Cólera-Morbo-Asiático.

Archivo Histórico Municipal de Valencia (AHMV). Libro de Actas, sesión 01-01-1859.

BANHAM, Reyner. La arquitectura del entorno bien climatizado. Buenos Aires: Ed. Infinito, 1975 [1969].

BASSEGODA NONELL, Juan. El gran Gaudí. Barcelona: Ausa, 1989.

BENITO GOERLICH, Daniel. La arquitectura del eclecticismo en Valencia. Vertientes de la arquitectura valenciana entre 1875 y 1925. Valencia: Ayuntamiento de Valencia, 1983.

CABRERA SENDRA, Inés. Arquitectura en Valencia 18331868. De la crisis del Academicismo a los historicismos. Tesis doctoral. Castellón: Universitat Jaume I, 2017.

CERDÁ SUNYER, Ildefonso. Teoría general de la urbanización y aplicación de sus principios y doctrinas a la reforma y ensanche de Barcelona. Vols. I y II. Madrid: Imprenta Española, 1867.

DUPUYTREN, Guillaume. Diccionario de ciencias médicas por una sociedad de los más celebres profesores de Europa. Madrid: Imprenta de Don Mateo Repullés, 1821.

ESPINOSA, Pedro Celestino. Manual de construcciones de albañilería. Madrid: Imprenta de Severiano Paz, 1859.

FLAQUER I REVAUD, Sílvia; PAGÉS I GILIBETS, Mª Teresa. Inventari d'artistes catalans que participaren als Salons de París fins I'any 1914. Barcelona: Diputació de Barcelona, 1986.

FORNÉS Y GURREA, Manuel. El arte de edificar. $2^{\text {a }}$ edición. Madrid: Mariano de Cabrerizo, 1857.

GARCÍA, Hortensia. 2016. "Cuando los médicos diseñaban la ciudad". Levante. El Mercantil Valenciano, 10.05.2016.

GER Y LÓBEZ, Florencio. Tratado de construcción civil. Texto. Badajoz: La Minerva Extremeña, 1898a.

GER Y LÓBEZ, Florencio. Tratado de construcción civil. Atlas. Badajoz: La Minerva Extremeña, 1898b.

GERLING, Daniel Max. American Wasteland: A Social and Cultural History of Excrement. PhD Dissertation. The University of Texas at Austin, 2012.

GIRARDIN, Jean. Lecciones de química elemental. BarceIona: Imprenta de José Matas, 1841.

93 BANHAM, Reyner, 1975, p. 29-44.

${ }^{94}$ GUASTAVINO, Rafael, 1893b, p. 15. 
GRAUS Ramón; ROSELL, Jaume; ROCA, Antoni. L'Escola Industrial de Barcelona. Cent anys d'ensenyament tècnic i d'arquitectura. Barcelona: Diputació, 2008.

GRUPO 2C. La Barcelona de Cerdà. Barcelona: Flor del Viento, 2009.

GUASTAVINO MORENO, Rafael. "Estudios sobre la higiene urbana (I)". El porvenir de la industria. Periódico semanal de Ciencias, Industria, Agricultura y Comercio, n. 20, 20-08-1875a, p. 347-348.

GUASTAVINO MORENO, Rafael. "Estudios sobre la higiene urbana (II)". El porvenir de la industria. Periódico semanal de Ciencias, Industria, Agricultura y Comercio n. 23, 11-09-1875b, p. 380-382.

GUASTAVINO MORENO, Rafael. "Estudios sobre la higiene urbana (III)". El porvenir de la industria. Periódico semanal de Ciencias, Industria, Agricultura y Comercio n. 27, 8-10-1875c, p. 458-459.

GUASTAVINO MORENO, Rafael. "Estudios sobre la higiene urbana (IV)". El porvenir de la industria. Periódico semanal de Ciencias, Industria, Agricultura y Comercio n. 29, 22-10-1875d, p. 502-503.

GUASTAVINO MORENO, Rafael. "Estudios sobre la higiene urbana (V)". El porvenir de la industria. Periódico semanal de Ciencias, Industria, Agricultura y Comercio n. 31, 5-11-1875e, p. 538-539.

GUASTAVINO MORENO, Rafael. "Construction of fireproof buildings". Patente concedida el 11 de agosto de 1885. En: WAITE, Diana; GIOIA, Patricia. United States Patents Held by the Rafael Guastavinos, Father and Son. APT Bulletin: The Journal of Preservation Technology, 1999, vol. 30, no 4, p. 59-156.

GUASTAVINO MORENO, Rafael. "Cohesive construction". The American Architect and Building News vol. XXVII, $n^{\circ} 739$, February 22, 1890, p. 123-126.

GUASTAVINO MORENO, Rafael. Essay on the theory and history of Cohesive Construction, applied especially to the timbrel vault. $2^{\text {a }}$ ed. Boston: Ticknor and Company, 1893a. En: GUASTAVINO MORENO, Rafael. Escritos sobre la construcción cohesiva. Madrid: CEHOPU / Instituto Juan de Herrera, 2006, p. 1-96.

GUASTAVINO MORENO, Rafael. La construcción cohesiva: su pasado, su presente, ¿su futuro?, Congreso Internacional de Arquitectos, Chicago. Conferencia dictada en 5-08-1893 publicada en un fascículo. Fuente: Avery Library, Columbia University, Nueva York, 1893b.

GUASTAVINO MORENO, Rafael. 1896. Prolegomenos on the Function of Masonry in Modern Architectural Structures (Part I). New York: Record and Guide Press, edición española de 1904 revisada por Ignacio Javier Gil Crespo y publicada en GUASTAVINO MORENO, Rafael. 2006. Escritos sobre la construcción cohesiva. Madrid: CEHOPU / Instituto Juan de Herrera, 2006, p. 97-122.

GUASTAVINO MORENO, Rafael. The Function of Masonry in Modern Architectural Structures (Part II). Boston: American Printing Co., 1904. En: GUASTAVINO MORENO, Rafael. Escritos sobre la construcción cohesiva. Madrid: CEHOPU / Instituto Juan de Herrera, 2006, p. 123-156.

GUASTAVINO MORENO, Rafael. Escritos sobre la construcción cohesiva. Madrid: CEHOPU / Instituto Juan de Herrera, 2006a.

GUASTAVINO SEIDEL, Rafael. An Architect and his Son. Maryland: Heritage Books, 2006b.

GWILT, Joseph. An Encyclopaedia of Architecture: historical, theoretical \& practical. Harlow: Longman, Brown, Green, Longmans \& Roberts, 1859.
GWILT, Joseph. An Encyclopaedia of Architecture: historical, theoretical \& practical. London: Longman \& Green, 1888.

HAILEY, Charlie. "From sleeping porch to sleeping machine: inverting traditions of fresh air in North America". Traditional Dwelling and Settlements Review, Vol. 20, n. 2, primavera 2009, p. 27-44.

HENRY, Alison; McCAIG, lain; WILLET, Clara; GODFRAIND, Sophie; STEWART, John (eds). 2015. Earth, Brick \& Terracotta. Practical Building Conservation Series. Burlington: Ashgate Publishing Company, Vol. I, 2015.

KNEIPP, Sebastian. So sollt Ihr Leben. Altenmunster: Jazzybee Verlag, 2015 [1889]. En https://www.kneipp. com/fileadmin/PDF/So-sollt-ihr-leben_SebastianKneipp.pdf (fecha de consulta: 14-04-2019).

LASHERAS PEÑA, Ana Belén. España en París. La imagen nacional en las Exposiciones Universales, 1855-1900. Santander: Universidad de Cantabria, 2009.

LAVEZZARI, Émile. "Étude de la Construction des Établissements Hospitaliers". Revue de l'Architecture et des Travaux Publics vol. 22, París, 1864, p. 180-205.

LLOPIS, Amando (VTM-Arquitectes); PERDIGÓN, Luis; TABERNER, Francisco. Cartografía histórica de la ciudad de Valencia (1608-1944). Vols. 1 y 2. Valencia: Faximil Edicions Digitals, 2004.

LUENGO PÉREZ, Noelia. La obra conservada de Rafael Guastavino Moreno en Cataluña. Estudio y análisis para su puesta en valor, Trabajo final de Máster en Conservación del Patrimonio Arquitectónico, Universitat Politècnica de València, 2016.

MARCOS Y BAUSÁ, Ricardo. Manual del albañil. $3^{\text {a }}$ edición. Madrid: Biblioteca Enciclopédica Popular Ilustrada, 1879.

MARTINEAU, Harriet. "How to make home un-healthy", Harper's New Monthly Magazine I (Jun.-Nov. 1850), p. 618-619.

MATALLANA, Mariano. Vocabulario de arquitectura civil. Madrid: Francisco Rodríguez, 1848.

MUÑOZ ÁLVAREZ, Javier. La modernidad de Cerdá: más allá del "Ensanche". Algunos apuntes de ingeniería y cultura. Madrid: Fundación Esteyco, 2009.

OCHSENDORF, John. Las bóvedas de Guastavino. El arte de la rasilla estructural. Barcelona: Ajuntament de Barcelona, 2014

PALOMERO GONZÁLEZ, José Antonio; ALVARIÑO SERRA, Patricia. "La importancia del higienismo y la potabilización del agua en la ciudad de Valencia (18601910)". Investigaciones Geográficas n. 65, enero-junio de 2016, p. 45-55.

ROBINSON, Charles. The improvement of towns and cities or the practical asis of civic aesthetics. New York \& London: G. P. Putnam's sons, 1901.

ROGENT I PEDROSA, Francisco; DOMÉNECH I MONTANER, Lluís. Arquitectura moderna de Barcelona, Barcelona: Parera y Cia, Editores, 1897.

ROSELL I COLOMINA, Jaume. "Rafael Guastavino i Moreno: enginy en l'arquitectura del segle XIX". En: AAVV. Ciència $i$ Tècnica als Països Catalans: una aproximacio biogràfica, Barcelona: Fundación Catalana per la Recerca, 1995.

ROS GARCÍA, Juan Manuel. "La fábrica de doble hoja en Madrid. Un siglo de cerramiento moderno". Informes de la Construcción vol. $56 \mathrm{n}^{\circ}$ 495, enero-febrero 2005, p. $57-71$

RUF MARTÍ, Lluis. L'aportació de Rafael Guastavino a l'exposició de Filadèlfia de 1876: Improving the health- 
fulness of Industrial towns, Barcelona: UPC-EPSEB, PFC, 2007.

SANCHO ARANGO, Antonino. Mejoras materiales de Valencia. Colección de artículos. Valencia: Imp. J. Mateo Garín, 1855.

SANCHO ARANGO, Antonino. Memoria para el Ensanche de Valencia. Valencia: Imprenta de la Regeneración Tipográfica, de Ignacio Boix, 1859.

TABERNER PASTOR, Francisco. Valencia entre el ensanche y la reforma interior. Valencia: Edicions Alfons el Magnànim, 1987.

TABERNER PASTOR, Francisco. "Representaciones cartográficas de la ciudad de Valencia: del manuscrito a la reproducción seriada". Treballs de la Societat Catalana de Geografia n. 77, junio 2014, p. 275-297.

VEGAS LÓPEZ-MANZANARES, Fernando. "Los orígenes valencianos en la obra de Guastavino". En: HUERTA Santiago. (ed.) Las bóvedas de Guastavino en América, Madrid: Instituto Juan de Herrera, 1999, p. 253- 270.
VEGAS, Fernando; MILETO, Camilla. "Guastavino y el eslabón perdido". En: Construyendo bóvedas tabicadas: actas del Simposio Internacional sobre bóvedas tabicadas. Valencia: Editorial Universitat Politècnica de València, 2012, p. 133-156.

VEGAS, Fernando; MILETO, Camilla; CANTERO, Víctor Manuel. "El arquitecto Rafael Guastavino (1842-1908): obra en cuatro actos". Ars Longa, Cuadernos de Arte, 2017, n. 26, p. 209-230.

VILLANUEVA, Juan de. Arte de Albañilería. Madrid: Francisco Martínez Dávila, 1827.

WIGHT, Peter Bonnett. "The Works of Rafael Guastavino. Part I. The Brickbuilder 10, abril 1901, 79-81.

ZARAGOZÁ, Arturo; VEGAS LÓPEZ-MANZANARES, Fernando. "Wider, Lighter, Faster. Building Vaults in the Medieval Mediterranean". En: FUENTES, Paula. WUNDERWALD, Anke. The art of vaulting, 2019, Berlín: Birkhäuser, p. 11-28. https://doi.org/10.1515/978303561 8358-002. 